\title{
Action potential recording from dielectrophoretically positioned neurons inside micro-wells of a planar microelectrode array
}

\begin{abstract}
To organise in-vitro neural networks at the cellular level and study their electrical patterns, we have fabricated using conventional photolithography, a 4 x 4 planar microelectrode array capable of confining a single neuron in the immediate vicinity of each electrode site, and guiding the outgrowth of processes toward neighbouring neurons using micro-wells and micro-trenches that have been developed using a negative photoresist (SU-8). In order to load a single neuron inside each micro-well, a simple system that utilises the phenomenon of dielectrophoresis is presented. This system provides a fast, effective and inexpensive way of assembling single-neuronper-electrode neural grids. Spontaneous and evoked action potentials with good signal-to-noise ratio were successfully recorded using a 16-channel acquisition/stimulation unit. On the other hand, SU-8 photoresist showed signs of toxicity, as neurons cultured on top of and adjacent to it did not grow processes and had irregular shapes. As a result, neural network formation was inhibited.
\end{abstract}

Keywords: planar microelectrode arrays, in-vitro neural networks, action potential, photolithography, SU-8, dielectrophoresis. 


\section{Introduction}

Planar microelectrode arrays (pMEAs) offer a non-invasive extracellular electrical interfacing for cultured neurons (Gross et al., 1977; Pine, 1980) and brain slices (Egert et al., 1998; Oka et al., 1999). These devices are manufactured using standard photolithographic techniques and comprise a two-dimensional array of cell-scale microelectrodes embedded on the surface of a non-conducting planar substrate where neurons can be cultured in-vitro. Apart from being non-invasive, the advantage of pMEAs is that they can provide a bi-directional way of communication since each electrode in the array can be used for recording and stimulation (Pine, 1980; Breckenridge et al., 1995; Wagenar et al., 2004), which has led to the development of hybrid neuro-electronic systems for applications such as controlling robot mobility (Marks, 2008).

In addition, past research has shown that cultures of neurons on pMEAs are quite sensitive to changes in their chemical environment, which translates into changes in the recorded patterns of their signalling activity (Gross et al., 1995). Due to this observation, several research groups have been using pMEAs as biosensors for pharmacological screening in order to reduce the need for animal experiments (Morefield et al., 2000; Chiappalone et al., 2003) and to identify substances on the basis of electrical activity (Gramowski et al., 2004). Nevertheless, these studies involved investigating the electrophysiological behaviour of high-density cultures randomly dispersed on pMEAs by examining population attributes such as bursting frequency and bursting duration, and could not reveal information regarding the dynamics of neural networks at the single-cell level. 
To organise single-neuron-per-electrode networks, several techniques for confining a single cell in the immediate vicinity of each microelectrode in the pMEA have been explored. Techniques involving the implementation of three-dimensional microstructures over the pMEA electrodes (Jimbo et al., 1993; Maher et al., 1999; Griscom et al., 2002; Suzuki et al., 2004; Morin et al., 2006), and chemically patterned growth substrates (Wyart et al., 2002; Nam et al., 2004; James et al., 2004) were used successfully. In the case of growth substrates, the pMEA is micro-stamped with proteins that promote neural adhesion to the substrate in order to organise them in a predetermined manner; however, it has been reported that cell survival is decreased due to the chemical modification of the substrate (Branch et al., 2000). On the other hand, three-dimensional microstructures on pMEAs are essentially cell-scale wells (micro-wells) created in an additional layer (such as silicon, SU-8, or agarose) that is embedded on top of the electrode array, and each well is connected to its neighbouring wells via micro-trenches (open) or micro-channels (closed) that guide the outgrowth of neurites. Nevertheless, the task of positioning a single neuron inside each micro-well of the pMEA is not straightforward. Neurons are usually loaded manually using glass micropipettes guided by micromanipulators (Maher et al., 1999; Suzuki et al., 2004; Claverol-Tinture et al., 2007), which is a time-consuming, workintensive procedure. Furthermore, the long period of time required for loading a few micro-wells could result in cells being damaged, which forbids the realisation of large-scale single-cell networks.

In order to address this problem and achieve fast loading of neurons on pMEAs, a solution can be found in a phenomenon first observed by Herbert Pohl, and termed dielectrophoresis (DEP), which describes the motion of particles subjected to a non- 
uniform electric field. According to DEP, if a non-uniform electric field is applied to a particle (neuron in this case) suspended in medium, the unequal field force will cause it to move toward the region of strongest or weakest field intensity depending on the dielectric properties of the particle relative to the suspended medium (Pohl, 1951). DEP has been previously used for positioning neurons on pMEAs. Heida et al. (2001b) investigated the negative DEP positioning of fetal cortical rat neurons on planar quadrupole microelectrodes, while Prasad et al. (2003) used positive DEP for positioning hippocampal rat neurons on pMEAs. Single-cell/particle patterning has also been demonstrated using dielectrophoretic traps (Prasad et al., 2004; Rosenthal and Voldman, 2005), nevertheless, there is no evidence of work involving the DEP positioning of neurons inside micro-wells.

In this article, we present extracellular action potential recordings obtained from DEP-created single-neuron-per-electrode networks cultured on pMEA devices that were embedded with a negative photoresist layer (SU-8 2015) onto which micro-wells and micro-trenches were created in order to confine the movement of neurons and guide their neurite growth. A technique for positioning individual neurons onto single electrode sites is also introduced. This was accomplished by using a combination of positive dielectrophoresis, image processing and an electronic switching board. 


\section{Materials and methods}

\section{1.pMEA fabrication}

The gold pMEAs used in this work (Fig. 1) are $38 \mathrm{~mm}$ long and $26 \mathrm{~mm}$ wide. Tracks $(20 \mu \mathrm{m}$ wide) extend from an array of $4 \times 4$ square shaped electrode sites (40 $\mu \mathrm{m} \times 40 \mu \mathrm{m}$ each), which are located at the centre of the device, and connect to 16 bonding pads ( 8 on each side of the device) with dimensions of $2 \mathrm{~mm} \times 2 \mathrm{~mm}$ each. In addition, there is a reference electrode below the electrode array with dimensions of $480 \mu \mathrm{m} \times 200 \mu \mathrm{m}$. The bonding pads are attached to insulated copper wires with crimp connectors using conductive epoxy (Chemtronics, USA), and the connections are insulated using quick set epoxy adhesive (RS Components Ltd, UK). An area of $15 \mathrm{~mm}$ x $10 \mathrm{~mm}$ around the electrodes is covered with a $38 \mu \mathrm{m}$ thick layer of cured SU-8 2015 photoresist, which has micro-wells and micro-trenches created into it. A single micro-well is located above each electrode site of the array and is $20 \mu \mathrm{m} \times 20 \mu \mathrm{m}$ in order to accommodate a single neuron of the same or smaller size. Each micro-well is connected to its neighbouring wells via a $5 \mu \mathrm{m}$ wide and $100 \mu \mathrm{m}$ long micro-trench.

The fabrication process is summarised in Fig. 2 and is divided into two parts. Initially, the electrode sites, tracks and bonding pads are defined on a gold coated glass substrate using a positive photoresist and a chromium mask, followed by a second step where the micro-wells and micro-trenches are implemented on top of the electrode sites using SU-8 2015 negative photoresist and a photographic emulsion on soda lime glass mask. The choice of using SU-8 2015 photoresist for this application 
lies in the fact that this particular photoresist is capable of producing thin films of 15 $\mu \mathrm{m}$ up to $38 \mu \mathrm{m}$ thickness with high aspect ratios.

The substrates used for the production of the pMEAs were gold-coated microscope glass slides, coated with $100 \mathrm{~nm} \mathrm{Au}$ on a $20 \mathrm{~nm}$ Ti seed layer at the Centre for Nanoscience and Technology (University of Sheffield, UK). Slides were cleaned in acetone at $55^{\circ} \mathrm{C}$ for 10 minutes, methanol for 5 minutes, rinsed in DI water and dried with nitrogen. They were then spin coated (Spin coater: Laurell, Model WS400B-6NPP/LITE, Laurell Technologies Corporation, North Wales, USA) with a positive photoresist (MICROPOSIT S1813, Rohm and Haas, UK) at 6000 r.p.m for 50 seconds and soft baked at $115{ }^{\circ} \mathrm{C}$ for 60 seconds. The photoresist-coated Au slides were manually aligned with the a chromium mask (Compugraphics International Ltd., UK), which defined the electrodes, tracks and bonding pads, and were exposed to UV for 50 seconds using a UV-light box (AZ 210, Mega Electronics, UK). Following exposure, slides were developed in Microposit 351 (Shipley, UK), rinsed with DI water and hard baked in a convection oven at $90{ }^{\circ} \mathrm{C}$ for 45 minutes.

The gold pattern was etched in an aqueous solution of $\mathrm{KI}(10 \% \mathrm{ww})$ and $\mathrm{I}_{2}(2.5 \%$ ww) for 2 minutes and the $\mathrm{Ti}$ seed layer was etched with $\mathrm{HCl}$ (37\% ww). The remaining photoresist was stripped by immersion in acetone for a few minutes, then methanol and finally rinsed with DI water and dried with nitrogen.

The second part of the fabrication process involved the implementation of the micro-wells and micro-trenches on top of pMEA electrode sites. To achieve this, the slides were cleaned again using the three stage cleaning process described earlier and 
were then placed on a hotplate for 30 minutes at $150{ }^{\circ} \mathrm{C}$ in order to remove excess humidity. SU-8 2015 (Microchem Corporation, USA) was spin-coated at 500 r.p.m for 10 seconds with an acceleration of 100 r.p.m/second to allow the resist to spread and cover the entire surface of the slide, and then ramped to a final speed of 1000 r.p.m at an acceleration of 300 r.p.m/second and held there for 30 seconds in order to achieve the desired resist thickness $(38 \mu \mathrm{m})$. The slides were then soft baked at $65^{\circ} \mathrm{C}$ for 2 minutes and at $95^{\circ} \mathrm{C}$ for 5 minutes.

Following soft baking, the edges of the pMEAs were immersed in acetone, methanol and DI water in order to remove the excess SU-8 that had accumulated during spin-coating and to expose the bonding pads and reference electrode located around the edges. The pMEAs were then aligned with the SU- 8 microstructure mask (JD Photo Tools, Oldham, UK) and exposed (wave-length $365 \mathrm{~nm}$, dose $150 \mathrm{~mJ} / \mathrm{cm}^{2}$ ) using a mask aligner (Ultra $\mu$ Line 7000 High Resolution Mask Aligner, Quintel Corporation, USA) in contact mode. After exposure, a post-exposure bake (PEB) was performed $\left(65^{\circ} \mathrm{C}\right.$ for 1 minute followed by $95^{\circ} \mathrm{C}$ for 5 minutes $)$. The slides were then agitated in SU-8 developer for 4 minutes and rinsed with isopropanol, DI water and dried with nitrogen. Inspection of the fabricated pMEAs was then carried out under the microscope to ensure that the micro-wells and micro-trenches were developed properly, followed by two hard bake steps to further cross link the SU-8, one on a hotplate at $150{ }^{\circ} \mathrm{C}$ for 30 minutes and the other in a convection oven at $75{ }^{\circ} \mathrm{C}$ for 90 minutes. 


\subsection{Cell culture}

Two types of cells were used in this work; postnatal rat cerebellar neurons for DEP-positioning and recording/stimulation experiments, and mouse hippocampal neurons of the cell line HT22. Unlike primary neurons, HT22 cells had the ability to proliferate, which made them unsuitable for single cell recordings; nevertheless, they were used to evaluate the single-cell positioning technique described here.

The postnatal rat neurons were obtained from the cerebella of seven-day-old Sprague Dawley rats. Briefly, the cerebella from six neonatal rats were dissected, minced with scalpels into $0.5 \mathrm{~mm}^{2}$ cubes, placed in ice-cold HBSS supplemented with $3 \mathrm{~g} / \mathrm{l}$ of BSA, and washed with HBSS three times. The extracellular matrix of the tissue was weakened by incubation at $30{ }^{\circ} \mathrm{C}$ in NeuroPrep ${ }^{\mathrm{TM}} / \mathrm{NeuroPapain}{ }^{\mathrm{TM}}$ (AMS Biotechnology, UK) solution (2 $\mathrm{mg}$ of NeuroPapain per $1 \mathrm{ml}$ of NeuroPrep) and isolated cells were obtained via mechanical trituration in Neurobasal ${ }^{\mathrm{TM}}$ (Invitrogen, UK) supplemented with 2\% B-27 Serum-Free Supplement (Invitrogen, UK), 2 mM GlutaMAX $^{\mathrm{TM}}$ (Invitrogen, UK), and $50 \mu \mathrm{g} / \mathrm{ml}$ of gentamicin (Sigma, UK). Cells were then counted using a hemocytometer and used in the DEP and recording/stimulation experiments described in the following sections.

The culture medium used for HT22 cells was Dulbecco's Modified Eagle's Medium or DMEM (Invitrogen, UK) supplemented with $10 \%$ fetal calf serum, $1 \%$ Penicillin-Streptomycin-Neomycin solution and $2 \mathrm{mM}$ L-glutamine (Sigma, UK). To passage the cells, the old medium was removed from the culture flask (T-25 flask) and disposed. In order to detach the cells from the surface of the flask $4 \mathrm{ml}$ of trypsin 
$0.25 \%$ EDTA (Sigma, UK) were added to the medium and incubated at $37{ }^{\circ} \mathrm{C}$ for 4 minutes. The action of trypsin was neutralised by adding $6 \mathrm{ml}$ of fresh culture medium and the suspension was centrifuged at 1400 r.p.m for 3 minutes. The trypsin/DMEM suspension was then removed and $8 \mathrm{ml}$ of fresh DMEM were added to re-suspend the cells. Some of the cells were then transferred to new flasks for subculture where $5 \mathrm{ml}$ of DMEM were added per flask, and the remaining cells were used for obtaining statistical data for the single-cell DEP positioning method described next.

\subsection{Dielectrophoretic positioning of neurons inside pMEA micro-wells}

\subsubsection{Single-cell positioning system}

The experimental set-up for single-cell positioning is based on positive DEP and is depicted in Fig. 3a. The system comprised a microscope (Nikon Eclipse 50i, Nikon Instruments Europe), a microscope camera (Dolphin F145B, Allied Vision Technologies, Germany), a function generator with an RS232 interface (FG-100, Digimess, UK), a digital oscilloscope (Iso-tech IDS 710, RS Components Ltd, UK), a data acquisition (DAQ) card (USB-6221, National Instruments, UK), and a home-built printed circuit board (PCB) for mounting the pMEA device. The PCB comprised 16-digitally controlled analogue CMOS switches (MM74HC4316, Fairchild Semiconductor) that were opened or closed by supplying a logic ' 0 ' or a logic ' 1 ' signal to their control terminals.

The output of each switch was connected to one of the electrodes in the pMEA and the inputs were all connected to the output of the function generator. The data 
acquisition card provided the 16-logic signals for controlling the state of the CMOS switches. The DAQ card, the function generator and the microscope camera were all controlled by Matlab (The MathWorks Ltd., UK) through a graphical user interface (GUI) programme (Fig. 4). The DAQ card and camera were controlled using Matlab's data acquisition toolbox and image acquisition toolbox respectively, and the function generator via the RS232 interface. The user interface allowed the operator to input the DEP parameters (frequency, amplitude), initialise or manually stop the experiment ('Start' and 'Stop' buttons), and to monitor the process through a preview window and an array of sixteen checkboxes that indicated if a micro-well had been loaded or not (ticked checkbox implied that micro-well had been loaded).

\subsubsection{Cell positioning protocol}

Initially, pMEAs and the ITO counter-electrode were sterilised using $70 \%$ ethanol followed by exposure to UV for 60 minutes (30 minute exposure for each side). The pMEAs were then coated with poly-D-lysine (PDL). Nevertheless, if PDL was introduced straight away to the surface of a pMEA, the surface tension would have prevented the water from entering the micro-wells (Maher et al., 1999). Therefore, the devices were first immersed in $95 \%$ ethanol for 5 minutes, and rinsed five times with sterile DI water. They were then immersed in a $50 \mu \mathrm{g} / \mathrm{ml}$ PDL solution for 24 hours at room temperature, rinsed 5 times with DI water and left to dry for another 24 hours before use.

To position neurons inside the micro-wells of the pMEA, the cells were subjected to a nonuniform electric field (frequency of $4.6 \mathrm{MHz}$ and amplitude $8 \mathrm{~V}_{\mathrm{pp}}$ ) produced between a counter-electrode formed using an ITO coated glass slide (CG-40IN-S215, 
Delta Technologies, USA), and the electrode sites of the array (Fig 3b). ITO was chosen in this set-up as it is transparent in nature and allows the microscope to focus on the micro-wells. Finite element analysis of this configuration was performed in order to predict the location of neurons on the electrode sites (see results section). A $100 \mu \mathrm{m}$ thick sealing film (Nescofilm, Bando Chemical, Japan) with an exposed area of approximately $16 \mathrm{~mm}^{2}$ was positioned on top of the pMEA, with the exposed area of the film surrounding the electrode sites of the device. The pMEA was then placed on a hotplate at $100{ }^{\circ} \mathrm{C}$ for 1 minute in order for the film to adhere to the SU-8 layer and form a liquid-tight chamber. The culture medium of the neurons from section 2.2 was removed and the cells were suspended in a low conductivity medium $(8.5 \%$ sucrose/ $0.3 \%$ glucose, adjusted to $25 \mu \mathrm{S} / \mathrm{cm}$ through the addition of $100 \mathrm{mM}$ PBS solution monitored using a conductivity meter (JENWAY 470, Barloworld Scientific Ltd, UK)) and washed three times. A small amount of cell suspension $(20 \mu \mathrm{l}$ containing 9000 cells or $45 \times 10^{4}$ cells $/ \mathrm{ml}$ ) was placed on the electrode sites. The ITO electrode was then placed over the electrode site area, thus enclosing a $1.6 \mathrm{~mm}^{3}$ volume of cell suspension in the immediate vicinity of the array.

Before the start of a cell positioning session, the micro-wells were aligned using the microscope's XY positioning manipulator with a bitmap image (Fig. 3c), which consists of 16 squares that overlay the image of the wells. The alignment of the wells with the squares in the bitmap image was achieved using ScopePhoto (Hangzhou Scopetek Opto-Electric Co., Ltd, China). These squares defined sixteen regions of interest for Matlab to process and detect the loading of cells into the micro-wells. Following alignment, ScopePhoto was deactivated and the Matlab GUI was employed. On clicking the 'Start' button, the software configured the microscope 
camera settings, and created a digital output object for the DAQ card. The function generator was then activated, CMOS switches were closed, and the camera captured an initial image. Following a $0.5 \mathrm{~s}$ delay, another image was captured and the software calculated the difference in pixel values between the two captured frames for the pixels included in the sixteen regions of interest. If a certain region of interest exceeded the threshold value that was set by the operator (i.e. a neuron was attracted to that area), the CMOS switch, which corresponded to that region, caused the signal to that electrode to be switched off (i.e. the switch was opened) in order to prevent more cells from being attracted to that electrode. In addition, the checkbox in the user interface, which corresponded to the same region, was ticked to indicate the loading of that particular micro-well. The capture-compare process was repeated until all sixteen micro-wells were loaded.

Following the completion of cell positioning (cerebellar rat neurons only), the cells were left for 60 minutes to adhere on the electrode sites of the pMEA. The ITO electrode was then removed, the sealing film peeled off, and the pMEA was disconnected from the PCB. The device was then placed inside a petri dish and $8 \mathrm{ml}$ of fresh culture medium (Neurobasal) were added. The cells were then checked under the microscope to make sure that they were still in place. Finally, the petri dish was sealed using a plastic lid and was incubated at $37{ }^{\circ} \mathrm{C}$ and $5 \% \mathrm{CO}_{2}$. 


\subsection{Recording/stimulation set-up}

Neural signals were obtained using a custom-designed low-power 16-channel analogue amplifier unit modified from Obeid et al. (2004) onto which pMEAs were mounted. Each of the sixteen channels had three analogue processing stages: a preamplifier, a differential amplifier, and a band pass filter. The gain of each channel was set to $70 \mathrm{~dB}$. The band pass filter had three high pass Bessel filter poles with a cut-off frequency of $100 \mathrm{~Hz}$ and five low pass Bessel filter poles with a cut-off frequency of $10 \mathrm{kHz}$. To multiplex and sample the amplified analogue signals a data acquisition card (DAQ) was used (PCI-6259, National Instruments, UK). The DAQ card was also used to provide voltage pulses for stimulation and to supply digital control signals to a switching board, which selected the desired pMEA electrode for stimulation.

To monitor and record the acquired signals LabView 7.1 (National Instruments, UK) was used. The sampling rate of the acquired signals was $50 \mathrm{kSamples} / \mathrm{s}$. Post processing of recorded neural activity was carried out using the Signal Processing Toolbox of Matlab 7 where signals were filtered using a $30^{\text {th }}$ order low pass filter with a cut-off frequency of $10 \mathrm{kHz}$. 


\section{Results}

\section{1.pMEA measurements}

Fig. 5 depicts the electrode sites, the SU-8 micro-wells and micro-trenches of the pMEA after the development process. The average thickness of the SU-8 layer was measured using a digital micrometer (LNR-50802J, LTL, accuracy: $\pm 2 \mu \mathrm{m}$ ) and was found to be $37.6 \mu \mathrm{m} \pm 1 \mu \mathrm{m}$ (average of 5 pMEAs, all measurements in this manuscript are expressed as mean \pm S.D). The dimensions of the electrode sites were measured using PhotoLite software and were $34.2 \pm 2.2 \mu \mathrm{m}$ x $34.2 \pm 2.2 \mu \mathrm{m}$ (average of 5 pMEAs) yielding an error of $14.5 \%$, which can be attributed to the fact that there was no intimate contact between the Au-coated slides and the mask during the fabrication process. Micro-well dimensions were $19.6 \pm 0.5 \mu \mathrm{m} \times 19.1 \pm 0.9 \mu \mathrm{m}$ at the top of the SU-8 layer and $17.2 \pm 0.5 \mu \mathrm{m} \times 16.3 \pm 0.5 \mu \mathrm{m}$ at the bottom (average of 5 pMEAs). This result indicated that the walls of the micro-wells had a negative slope. On the other hand, the width of the micro-trenches varied between $4.4 \mu \mathrm{m}$ and $1.1 \mu \mathrm{m}$ within a single device $(3.2 \pm 1.2 \mu \mathrm{m}$, average of the 8 micro-trenches of the pMEA device in fig. 5). This large variation was due to the poor resolution of the photographic emulsion mask used for the SU-8 layer patterning.

The impedance of the sixteen electrode sites was determined using an impedance analysis instrument (PSM 1735 NumetriQ + IAI, N4L, UK) and was found to be $2.2 \mathrm{M} \Omega \pm 1.8 \mathrm{M} \Omega$ at $1 \mathrm{kHz}$, which is an expected result for Au electrodes that have not been platinised (Gross et al., 1977; Boppart et al., 1992; Nisch et al., 1994). 


\subsection{Single-Cell positioning}

The electrical field distribution over the surface of a single pMEA micro-well was determined using two-dimensional finite element analysis with Maxwell SV (Ansoft, USA) to estimate the position of neurons on the electrode sites and is illustrated in Fig. 6. Here, the walls of the SU-8 micro-well were drawn having a negative slope to resemble the actual micro-well profile. The distribution of the electrical field indicates that the high field regions (red) are located at the bottom edges of the micro-well. The electrical field also appears to be strong at the top edges of the micro-well; however, neurons would be drawn to the bottom since the maximum is located there.

The cell positioning process can be viewed in the video, which accompanies this manuscript (Vid. 1, the reader is referred to the web version of this article). The arrows in the video indicate the movement of a few HT22 cells toward nearby electrode sites. It can be clearly seen that the direction of their movement changes when Matlab recognises the loading of a cell inside a micro-well, and switches off the field from the corresponding microelectrode to prevent more electrodes from being loaded.

Fig. 7a to $7 \mathrm{f}$ illustrate frame by frame the loading of four micro-wells with neurons as a result of dielectrophoretic trapping. The timing between the frames is $417 \mathrm{~ms}$. The arrows in the images indicate the movement of a few cells toward nearby electrode sites, while the 'DEP Off' sign points out that the electric field has been switched off at that particular microelectrode. The time required for loading a single micro-well varied between a few hundreds of a second and a few seconds depending 
on the position of the cells before the application of the electric field. On the other hand, the loading of a whole pMEA varied between 5 and 35 seconds.

From these images one can observe that cells were attracted toward the sides of the micro-wells since the high field regions were located there. Each of the top two micro-wells had only one cell nearby, which was attracted on top of the electrode site. On the other hand, the bottom two wells had a few cells close to them. Once a cell was positioned inside each one of them and the cell-positioning software switched the electric field off, the direction of movement of the cells that were still outside changed and they started moving away from the micro-wells. One thing that should be pointed out is that the bottom-right micro-well seems to be loaded with something other than a cell (possibly debris), nevertheless, the software recognised that something was loaded and turned off the electric field.

It was also possible to attract more than one cell inside a single micro-well, either because two neurons were close to each other or were attached together. Another observation made during the single-cell positioning experiments, can be viewed in Fig. 8a. Here, the neurons indicated by the arrows have been attracted to the tracks of electrode sites that are exposed (not covered by SU-8), as there are micro-trenches that extend across them. The biggest problem though was the presence of air bubbles in the micro-wells, which made them appear dark due to diffraction of light (Fig. 8b, micro-well indicated by arrow). In most cases it was difficult for the software to recognise the attraction of a cell to these dark wells and switch off the signal, which resulted in several cells being trapped. 
In order to determine the optimum cell concentration for the single-cell positioning experiments and minimise the loading of micro-wells with more than one cell, twenty cell positioning sessions were carried out at two different cell concentrations $\left(92 \times 10^{4}\right.$ cells $/ \mathrm{ml}$ and $45 \times 10^{4}$ cells/ml) using HT22 cells (10 sessions per concentration). Fig. 9 shows the statistics obtained from these experiments.

While the percentage of micro-wells loaded with a single neuron was almost the same for both cases ( $45 \%$ for the higher and $43 \%$ for the lower concentration), it can be seen that the lower concentration used resulted in a significantly lower percentage of wells loaded with more than one neuron. The area labelled 'unknown' stands for the micro-wells that were too dark to observe any movement due to the presence of air bubbles. To eliminate air bubbles cell-free DEP medium was introduced to the micro-wells pMEAs before the addition of cells, however, this only minimised the problem. Sonication was also considered as a solution, nevertheless, it was abandoned as it caused damage to the SU-8 microstructures and etched away the gold layer.

The loading of micro-wells with more than one cell was not only due to high cell concentration. It was calculated that on average Matlab required $417 \mathrm{~ms}$ in order to finish checking all the wells, capture the next frame and start checking again. Hence, it was possible that more cells were loaded by the time the entire program commands were executed, which was inevitable since the code was executed sequentially. It is, therefore, believed that the use of parallel programming could reduce the number of wells loaded with more than one cell even more. Finally, the fact that several cells remain floating around the SU-8 microstructure area after the end of a DEP positioning session introduces the possibility that some of these free-falling cells 
might land inside micro-wells. Therefore, a flow device, which incorporates an inlet and an outlet for the cells, is considered for the future.

\subsection{Recording/stimulation}

Action potentials were successfully obtained from two pMEAs (four devices were used in total, labelled pMEA 1 - pMEA 4) that were DEP-loaded with postnatal rat cerebellar neurons after 24 hours in-vitro. Although all micro-wells of pMEA 1 were loaded with cells ( 7 out of 16 or $44 \%$ of the wells had a single cell), recordings were only obtained from 9 electrodes. Devices pMEA 2 and pMEA 3 did not demonstrate any electrical activity, while action potentials were recorded from only one cell of pMEA 4. It was likely that a large percentage of the cells did not survive the DEP positioning session, in particular the part were they were left on the pMEA for one hour without incubation in order to adhere to the electrode sites. This was confirmed by observing the cells after 24 hours in-vitro where it was noticed that micro-wells previously occupied by cells that did not demonstrate electrical activity were empty after this period of time. It was also observed that during DEP positioning, some cells 'squeezed' inside the micro-trenches due to the presence of the high field gradient there, which is also likely to be a reason for cell damage and death. On the other hand, the reason could have been that not all the cells were neurons since there was a small percentage of glial cells present in the suspension (according to Brewer et al. (1993) the use of Neurobasal/B-27 reduces glial cell growth to less than $0.5 \%$ ).

Nonetheless, spontaneous bursts and single events with amplitudes ranging from $10 \mu \mathrm{V}_{\text {p-p }}$ to $325 \mu \mathrm{V}_{\mathrm{p} \text {-p }}$ were recorded (Fig. 10), with the majority of signals being in the range $10-100 \mu \mathrm{V}_{\mathrm{p}-\mathrm{p}}$ and $10.7 \%$ having amplitudes greater than $100 \mu \mathrm{V}_{\mathrm{p}-\mathrm{p}}$. Neurons 
inside the micro-wells were also stimulated in order evoke action potentials. Fig. 11 shows an action potential detected at channel 10 of pMEA 4 after $115 \mathrm{~ms}$ of applying two biphasic voltage pulses (positive then negative) with a duration of $500 \mu$ s and amplitude of $1 \mathrm{~V}$ each. These specific parameters were chosen, as Wagenaar et al. (2004) have demonstrated that positive-then-negative biphasic voltage pulses are much more effective for stimulating neurons than current pulses. Data collected from this group also indicated that for a pulse duration of $500 \mu$ s the number of responses to stimuli was at maximum. In our stimulation experiment, the number of pulses used for a single stimulation event was varied between 1 and 20, the pulse amplitude was varied between $100 \mathrm{mV}$ and $1 \mathrm{~V}$, and the pulse duration was varied between $100 \mu \mathrm{s}$ and $1 \mathrm{~ms}$. Different waveform shapes were also tried, however, responses were only obtained with the parameter mentioned earlier. Even so, only a limited number of evoked responses was achieved due to the high impedance of our electrodes. We did not attempt to use voltages higher than $1 \mathrm{~V}$ for stimulation in order to avoid electrolysis.

Recording/stimulation sessions lasted a total of six days. Although control neurons grown on PDL-coated glass coverslips showed process outgrowth and network formation, during this period of time we did not observe neurites emerging from the neurons cultured inside the micro-wells of the pMEAs, and we did not obtain any signal patterns that indicated action potential conduction from one cell to another. To eliminate the possibility of DEP-positioning being the reason for this, rat cerebellar neurons were randomly dispersed on the electrode site area of two PDL-coated pMEA devices to allow the cells to fall inside the micro-wells. Recordings were obtained for a total of 21 days for these two devices. Once more we 
did not detect any outgrowing processes neither from the cells that had fallen inside the micro-wells, nor from the ones growing on top of the SU-8 layer. In addition, cells had irregular shapes and did not appear do be flat as the ones grown on glass coverslips (Fig 12).

Spontaneous and evoked signals were recorded as before. Signal amplitudes were between $9 \mu \mathrm{V}_{\mathrm{p}-\mathrm{p}}$ and $708 \mu \mathrm{V}_{\mathrm{p}-\mathrm{p}}$ (16\% of action potentials had amplitudes greater than $100 \mu \mathrm{V}_{\mathrm{p}-\mathrm{p}}$ ). Evoked action potentials had a mean latency (time between the end of the stimulation pulse and the evoked spike) of $57 \pm 31 \mathrm{~ms}(20 \mathrm{~ms}-120 \mathrm{~ms})$. Similar response times have been reported in the literature (Wagenaar et al., 2004; Merz and Fromherz, 2005; Berdondini et al., 2006).

\section{Discussion}

This article has demonstrated that action potential recordings can be acquired from neurons that were DEP-positioned inside 3D microstructures of pMEAs used for neural network patterning. It was found that $43 \%$ of the micro-wells were successfully loaded with a single cell; however, due to the presence of air bubbles, which made several micro-wells appear dark, it was difficult to observe the number of cells positioned in the remaining wells and assess the true accuracy of this technique. It has been reported that low AC fields do not seem to affect cell survival (Heida et al., 2001a) and that DEP forces cause a subtle increase in cell stress levels that do not affect cell growth (Huang et al., 2002). On the other hand, in our experiments only $16 \%$ of neurons survived DEP-positioning after 24 hours in-vitro. We suspect that this was because the cells were left in the DEP buffer medium and outside the incubator 
for an hour in order to adhere to the electrode sites, and/or because some cells squeezed inside the micro-trenches, and due to culture contamination since the ITO counter-electrode had to be lifted when cells were introduced. Therefore, we are considering integrating the pMEA, counter-electrode and a flow cell into a single device in order to realise a set-up less prone to infection, and transferring our DEPpositioning system inside an incubator. The purpose of the flow cell will be to guide the flow of cells directly above the micro-well area and to ensure that no free-falling neurons remain near the micro-wells following DEP-positioning. However, due to the flow of the cell suspension it is possible that DEP-trapped cells will be removed from the wells; therefore instead of switching off the electric field completely, the electrodes that have trapped neurons on top of them could be switched to a lower potential sufficient to hold the cells in place but weak enough to prevent the attraction of further ones. Before the introduction of the neuron suspension, the inlet of the flow cell could be connected to a $\mathrm{CO}_{2}$ line to remove air bubbles from the wells, followed by the addition of cell-free DEP buffer and then cells.

The technique used for loading single-cells on single electrode sites could prove to be beneficial for this field of neuroscience, as it will reduce the amount of time needed for loading single-cells using micropipettes, during which the cells become stressed, and allow the realisation of large-scale single-cell networks. DEPpositioning could also develop into a useful tool for separating neurons from glial cells since the DEP force depends on the dielectric properties of the cells, the frequency and the amplitude of the applied AC electric field, and the conductivity of the DEP buffer. As reported by Prasad et al. (2004), the positioning of glial cells on top of electrode sites was avoided by using a buffer medium with a conductivity of 
$1.2 \mathrm{mS} / \mathrm{cm}(250 \mathrm{mM}$ sucrose/1640 RPMI, $\mathrm{pH}$ of 7.48), an AC electric field with voltage amplitude of $8 \mathrm{~V}_{\mathrm{p}-\mathrm{p}}$ and a frequency of $4.6 \mathrm{MHz}$. At these conditions postnatal rat neurons experienced positive DEP while glial cells experienced negative DEP (it was determined that glial cells experienced positive DEP at lower frequencies - 152 $\mathrm{kHz}$ ). On the other hand, questions might be raised regarding separation of glial cells from neurons before differentiation. Nevertheless, there is recent evidence that neural stem/precursor cells (NSPCs) E12.5, which generate primarily neurons, and E16.5, which are more likely to form astrocytes, follow the trend of the cells they will preferentially differentiate into. Flanagan et al. (2008) demonstrated that E12.5 cells experienced positive DEP at higher frequencies, while E16.5 experienced positive DEP at lower frequencies. Although these two research groups used different cells, DEP devices, DEP media, and methodology, the frequencies they both reported for positive DEP are similar.

We realise that our pMEA device design has a few drawbacks associated with it. The high impedance of the electrode sites did not allow effective stimulation of neurons since limited evoked responses were observed. In addition, the lack of track insulation resulted in cells being attracted to exposed pMEA tracks and entering micro-trenches during DEP positioning, as well as shunting of neural signals. Platinum black deposition (Novak and Wheeler, 1988; Bove et al., 1995; Oka et al., 1999; James et al., 2004) is being considered for lowering the electrode impedance, and silicon nitride (Kovacs et al., 1994; Nisch et al., 1994; Nam et al., 2004) for insulating the tracks and the electrode site areas beneath the entrance of microtrenches. These features were absent from our pMEAs due to lack of necessary 
resources. Nonetheless, our main concern regarding the device design is the effect of SU-8 on neuron growth.

The main objective of our system was to realise neural networks at the single-cell level and study their signal patterns. Unfortunately, the absence of neurites from the cells grown inside the micro-wells of pMEAs compromised the experiments. The literature had very few references regarding the growth of neurons on SU-8; nevertheless, some useful conclusions were drawn. Initially, Voskerician et al. (2003) reported that SU-8 5, along with other materials (gold, silicon nitride, silicon dioxide, silicon), appeared to be biocompatible and demonstrated reduced biofouling when implanted in the back of Sprague-Dawley rats. Similar to the SU-8-on-pMEA approach described here was the work by Merz and Fromherz (2005). They succeeded in organising a network of single-snail neurons by placing the cells inside a $4 \mathrm{x} 4$ grid of SU-8 10 pits that were sitting directly on open-gate field-effect transistors for recording and a capacitor for stimulation. The pits were connected with $14 \mu \mathrm{m}$ wide grooves in order to guide the outgrowth of processes. Although, their approach presented proof-of-principle, as they observed repeatable spontaneous and evoked neural activity patterns, it also had a major defect. Out of more than two hundred devices used, with sixteen neurons in each of them, they observed synaptic connection between four neurons in only one, and that only $23 \%$ of the neurons inside the pits managed to grow neurites.

Another similar approach is the one by Zhang et al. (2006). Here, rat hippocampal neurons were placed inside SU-8 5 micro-wells $50 \mu \mathrm{m}$ to $100 \mu \mathrm{m}$ in diameter that were connected with neighbouring ones by $20 \mu \mathrm{m}$ to $40 \mu \mathrm{m}$ wide micro-trenches. 
Their set-up did not include electrodes at the bottom of the wells; however, recordings were obtained using whole-cell patch clamping. Apart from the SU-8 microstructures, neurons were also grown on glass coverslips as controls. Interestingly, the group observed that only a small number of neurites extended from neurons inside the SU-8 wells, whereas multiple processes were visible in the cells grown on glass. They also observed that the presence of the SU-8 barrier managed to restrict neural process growth within the pattern in most of the cases, nevertheless, it was also noticed that some neurites migrated onto the SU-8 covered region of the device. It was reported that cells whose neurites crossed the barrier shrank to an irregular shape.

The work of Merz and Fromherz (2005) and Zhang et al. (2006) along with the observations made in our experiments provide considerable evidence to support that SU-8 impedes the proper development of neural cells; however, there was no indication of cell death. On the other hand, a recent research by Vernekar et al. (2008) showed that less than $10 \%$ of primary neurons survived when cultured on top of or adjacent to SU-8 2000. The experiments conducted by this group involved the use of fluorescent probes for measuring the viability of primary rat neurons cultured adjacent to or on top of SU-8 2000 films with thickness equal or greater than $100 \mu \mathrm{m}$. It was concluded that the poor biocompatibility of SU-8 2000 was due to toxic leaching from SU-8 2000 components and poor cell adhesion. The group also demonstrated that the viability of neurons was up to $86.4 \%$ when SU-8 was coated with $25 \mu$ m of parylene in combination with heat and sonication in isopropanol treatments.

While the experiments conducted by Merz and Fromherz (2005) and Zhang et al., (2006) showed that some neurons managed to grow processes and were capable of 
firing action potentials over long periods of time, neurite growth was not observed in the experiments described here nor in the work by Vernekar et al., (2008).

Vernekar et al., (2008) suggested that there is a correlation between the amount of SU-8 in a neural recording/stimulating device and the potential toxicity (they used films $\geq 100 \mu \mathrm{m}$ in thickness). For instance, the thickness of the SU-8 layer used by Zhang et al., (2006) was $5 \mu \mathrm{m}$, the one by Merz and Fromherz (2005) ranged between $15 \mu \mathrm{m}$ and $30 \mu \mathrm{m}$ (unfortunately the authors did not specify in which devices they observed most of the neurite growth, e.g. were there more neurites growing in the 15 $\mu \mathrm{m}$ devices than the $30 \mu \mathrm{m}$ ?). Hence, it is possible that a small amount of SU-8 in a device (e.g. $5 \mu \mathrm{m}$ ) may result in lack of normal neuron maturation and normal neurite growth, while increasing the amount substantially may induce neuronal death.

Although this could be true, there are several other variables to consider, like the type of cells used, the culture environment, differences in the fabrication process, the type of SU-8 used. For instance, Merz and Fromherz (2005) and Zhang et al., (2006) used the original SU-8 formulation, while the work described here and the experiments by Vernekar et al., (2008) utilised the SU-8 2000 formulation. The first SU-8 formulation uses gamma-butyrolacetone as the solvent, while the solvent in SU-8 2000 is cyclopentenone, which has been recently found to induce neuronal apoptosis and enhance neuro-degeneration (Musiek et al., 2007). Unless an effective method for solving the toxicity problem of the photoresists is found, other materials with better biocompatibility have to be investigated. 


\section{Acknowledgements}

The writers would like to thank Dr. George Kass (School of Biomedical and Molecular Sciences, University of Surrey, Guildford, UK) for providing the HT22 neurons, Dr. Karen Kirkby (Advanced Technology Institute, University of Surrey, Guildford, UK) for providing access to clean room facilities, Dr. Serge Cirovic (Centre for Biomedical Engineering, University of Surrey, Guildford, UK) for lending us the USB-6221 DAQ card, and EPSRC for funding this research. 


\section{References}

Berdondini L, Chiappalone M, van der Wal P D, Imfeld K, de Rooij N F, KoudelkaHep M, Tedesco M, Martinoia S, van Pelt J, Le Masson G, Garenne A. A microelectrode array (MEA) integrated with clustering structures for investigating in vitro neurodynamics in confined interconnected sub-populations of neurons. Sens Actuators B 2006;114:530-541.

Boppart SA, Wheeler BC, Wallace CS. A Flexible Perforated Microelectrode Array for Extended Neural Recordings. IEEE Trans Biomed Eng 1992;39:37-42.

Bove M, Grattarola M, Martinoia S, Verreschi G. Interfacing cultured neurons to planar substrate microelectrodes: characterization of the neuron-to-microelectrode junction. Bioelectrochem Bioenerg 1995;38:255-265.

Branch DW, Wheeler BC, Brewer GJ, Leckband DE. Long-Term Maintenance of Patterns of Hippocampal Pyramidal Cells on Substrates of Polyethylene Glycol and Microstamped Polylysine. IEEE Trans Biomed Eng 2000;47:290-300.

Breckenridge LJ, Wilson RJA, Connolly P, Curtis ASG, Dow JAT, Blackshaw SE, Wilkinson CDW. Advantages of Using Microfabricated Extracellular Electrodes for In Vitro Neuronal Recording. J Neurosci Res 1995;42:266-276. 
Brewer GJ, Torricelli JR, Evege EK, Price PJ. Optimized Survival of Hippocampal Neurons in B27-Supplemented Neurobasal, a New Serum-free Medium Combination. J Neurosci Res 1993;35:567-576.

Chiappalone M, Vato A, Tedesco M(B), Marcoli M, Davide F, Martinoia S. Networks of neurons coupled to microelectrode arrays: a neuronal sensory system for pharmacological applications. Biosens Bioelectron 2003;18:627-634.

Claverol-Tinture E, Cabestany J, Rosell X. Multisite Recording of Extracellular Potentials Produced by Microchannel-Confined Neurons In-Vitro. IEEE Trans Biomed Eng 2007;54:331-335.

Egert U, Schlosshauer B, Fennrich S, Nisch W, Fejtl M, Knott T, Muller T, Hammerle H. A novel organotypic long-term culture of the rat hippocampus on substrate-integrated multielectrode arrays. Brain Res Protoc 1998;2:229-242.

Flanagan LA, Lu J, Wang L, Marchenko SA, Jeon NL, Lee AP, Monuki ES. Unique Dielectric Properties Distinguish Stem Cells and Their Differentiated Progeny. Stem Cells 2008;26:656-665.

Gramowski A, Jugelt K, Weiss D, Gross W. Substance identification by quantitative characterization of oscillatory activity in murine spinal cord networks on microelectrode arrays. Eur J Neurosci 2004;19:2815-2825. 
Griscom L, Degenaar P, LePioufle B, Tamiya E, Fujita H. Techniques for patterning and guidance of primary culture neurons on micro-electrode arrays. Sens Actuators B 2002;83:15-21.

Gross GW, Rhoades BK. The use of neuronal networks on multielectrode arrays as biosensors. Biosens Bioelectron 1995;10:553-567.

Gross GW, Rieske E, Kreutzberg GW, Meyer A. A new fixed-array multimicroelectrode system designed for long-term monitoring of extracellular single unit neuronal activity in vitro. Neurosci Lett 1977;6:101-105.

Heida T, Vulto P, Rutten WLC, Marani E. Viability of dielectrophoretically trapped neural cortical cells in culture. J Neurosci Methods 2001a;110:37-44.

Heida T, Rutten WLC, Marani E. Dielectrophoretic Trapping of Dissociated Fetal Cortical Rat Neurons. IEEE Trans Biomed Eng 2001b;48:921-930.

Huang Y, Joo S, Duhon M, Heller M, Wallace B, Xu X. Dielectrophoretic Cell Separation and Gene Expression Profiling on Microelectronic Chip Arrays. Anal Chem 2002;74:3362-3371.

James CD, Spence AJH, Dowell-Mesfin NM, Hussain RJ, Smith KL, Craighead HG, Isaacson MS, Shain W, Turner JN. Extracellular Recordings From Patterned Neuronal Networks Using Planar Microelectrode Arrays. IEEE Trans Biomed Eng 2004;51:1640-1648. 
Jimbo Y, Robinson HPC, Kawana A. Simultaneous Measurement of Intracellular Calcium and Electrical Activity from Patterned Neural Networks in Culture. IEEE Trans Biomed Eng 1993;40:804-810.

Kovacs GTA, Storment CW, Halks-Miller M, Belczynski CR Jr, Della Santina CC, Lewis ER, Maluf NI. Silicon-Substrate Microelectrode Arrays for Parallel Recording of Neural Activity in Peripheral and Cranial Nerves. IEEE Trans Biomed Eng 1994;41:567-577.

Maher MP, Pine J, Wright J, Tai Y-C. The neurochip: a new multielectrode device for stimulating and recording from cultured neurons. J Neurosci Methods 1999;87:45-56.

Marks P. Rise of the rat-brained robots. New Sci 2008;2669: 22-23.

Merz M, Fromherz P. Silicon Chip Interfaced with a Geometrically Defined Net of Snail Neurons. Adv Funct Mater 2005;15:739-744.

Morefield SI, Keefer EW, Chapman KD, Gross GW. Drug evaluations using neuronal networks cultured on microelectrode arrays. Biosens Bioelectron 2000;15:383-396.

Morin F, Nishimura N, Griscom L, LePioufle B, Fujita H, Takamura Y, Tamiyaa E. Constraining the connectivity of neuronal networks cultured on microelectrode arrays with microfluidic techniques: A step towards neuron-based functional chips. Biosens Bioelectron 2006;21:1093-1100. 
Musiek ES, McLaughlin B, Morrow JD. Electrophilic Cyclopentenone Isoprostanes in Neurodegeneration. J Mol Neurosci 2007;33:80-86.

Nam Y, Chang JC, Wheeler BC, Brewer GJ. Gold-Coated Microelectrode Array With Thiol Linked Self-Assembled Monolayers for Engineering Neuronal Cultures. IEEE Trans Biomed Eng 2004;51:158-165.

Nisch W, Bock J, Egert U, Hammerle H, Mohr A. A thin film microelectrode array for monitoring extracellular neuronal activity in vitro. Biosens Bioelectron 1994;9:737-741.

Novak JL, Wheeler BC. Multisite hippocampal slice recording and stimulation using a 32 element microelectrode array. J Neurosci Methods 1988;23:149-159.

Obeid I, Nicolelis MAL, Wolf PD. A low power multichannel analog front end for portable neural signal recordings. J Neurosci Methods 2004;133:27-32.

Oka H, Shimono K, Ogawa R, Sugihara H, Taketani M. A new planar multielectrode array for extracellular recording: application to hippocampal acute slice. J Neurosci Methods 1999;93:61-67.

Pine J. Recording Action Potentials from Cultured Neurons with Extracellular Microcircuit Electrodes. J Neurosci Methods 1980;2:19-31. 
Pohl HA. The Motion and Precipitation of Suspensoids in Divergent Electric Fields. J Appl Phys 1951;22:869-871.

Prasad S, Yang M, Zhang X, Ozkan CS, Ozkan M. Electric Field Assisted Patterning of Neuronal Networks for the study of Brain Functions. Biomed Microdevices 2003;5:125-137.

Prasad S, Zhang X, Yang M, Ni Y, Parpura V, Ozkan CS, Ozkan, M. Separation of individual neurons using dielectrophoretic alternative current fields. J Neurosci Methods 2004;135:79-88.

Rosenthal A, Voldman J. Dielectrophoretic Traps for Single-Particle Patterning. Biophys J 2005;88:2193-2205.

Suzuki I, Sugio Y, Jimbo Y, Yasuda K. Individual-Cell-Based Electrophysiological Measurement of a Topographically Controlled Neuronal Network Pattern Using Agarose Architecture with a Multi-Electrode Array. Jap J Appl Phys 2004;43:L403L406.

Vernekar V, Cullen D, Fogleman N, Choi Y, García AJ, Allen MG, Brewer GJ, LaPlaca MC. SU-8 2000 rendered cytocompatible for neuronal bioMEMS applications. J Biomed Mater Res A 2008; Article online in advance of print [http://www3.interscience.wiley.com/cgi-bin/fulltext/118823842/HTMLSTART]. 
Voskerician G, Shive MS, Shawgo RS, von Recum H, Anderson JM, Cima MJ, Langer R. Biocompatibility and biofouling of MEMS drug delivery devices. Biomaterials 2003;24:1959-1967.

Wagenaar DA, Pine J, Potter SM. Effective parameters for stimulation of dissociated cultures using multi-electrode arrays. J Neurosci Methods 2004;138:27-37.

Wyart C, Ybert C, Bourdieu L, Herr C, Prinz C, Chatenay D. Constrained synaptic connectivity in functional mammalian neuronal networks grown on patterned surfaces. J Neurosci Methods 2002;117:123-131.

Zhang J, Venkataramani S, Xu H, Song Y-K, Song H-K, Palmore G, Fallon J, Nurmikko A. Combined topographical and chemical micropatterns for templating neuronal networks. Biomaterials 2006;27:5734-5739. 
Figures and Legends

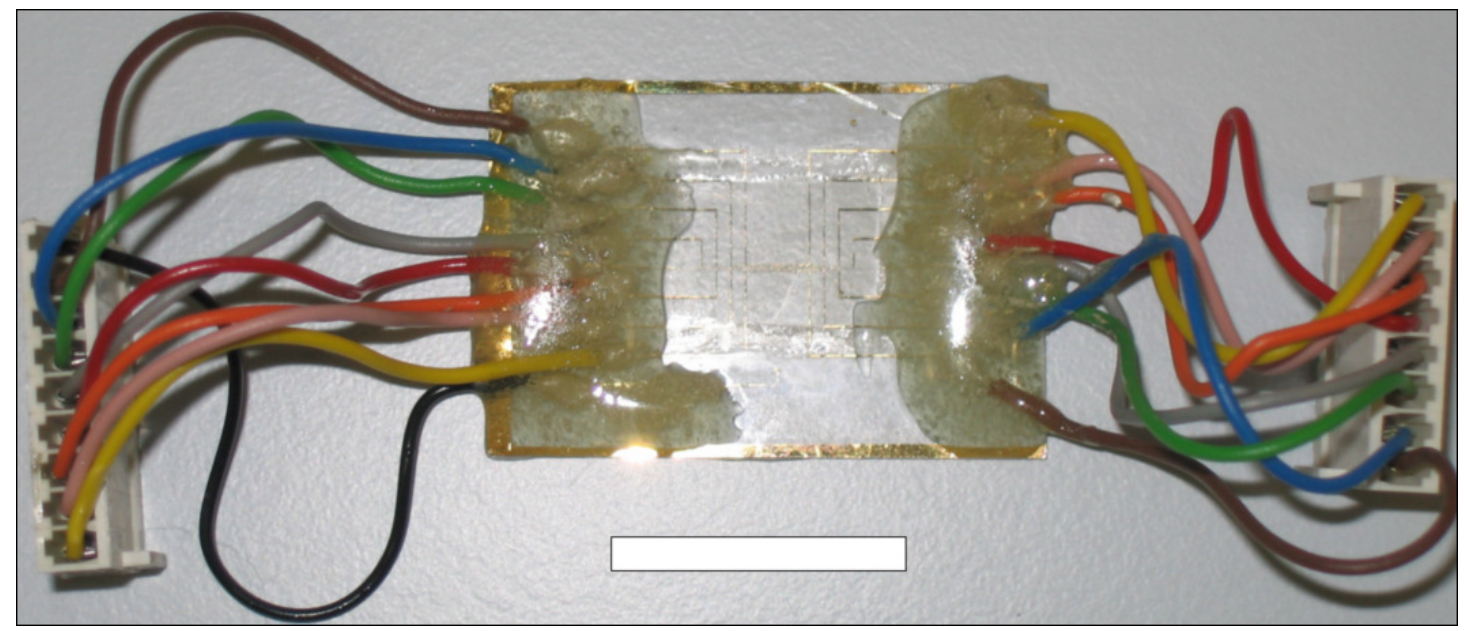

Fig. 1. Planar microelectrode array embedded with SU-8 micro-wells and microtrenches. The device is $38 \mathrm{~mm}$ long and $26 \mathrm{~mm}$ wide. Scale bar is $2 \mathrm{~cm}$ long. 

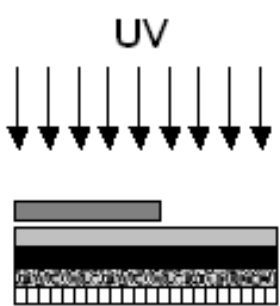

a

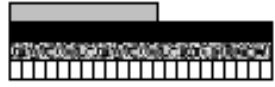

b

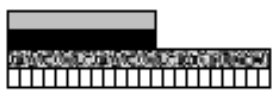

C

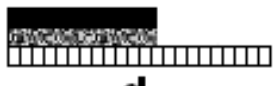

d
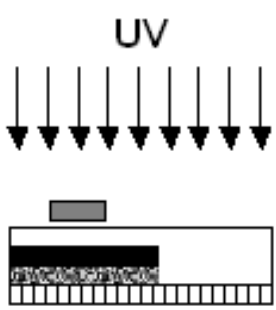

e

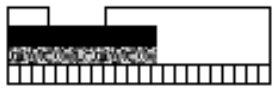

f
Mask

Positive photoresist

$\mathrm{Au}$

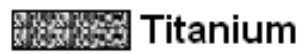

एण) Glass

SU8-2015

Fig. 2. pMEA fabrication process. (a) Positive photoresist-coated Au glass slides are exposed to UV through a chromium mask, which defines the bonding pads, tracks, and electrode sites of the array. (b) Slides are immersed in photoresist developer to remove the photoresist that has been exposed to UV. (c) Following a hard bake step, the Au areas, which are no longer protected by the photoresist, are etched away using an aqueous solution of KI. (d) The titanium seed layer is etched away in HCL, and the remaining photoresist covering the gold electrodes, tracks and bonding pads is removed in acetone. (e) The Au pMEA is spin coated with a $38 \mu$ m thick SU-8 layer, which is then soft baked, aligned using a mask aligner with a second mask that defines the micro-wells and micro-trenches, and exposed. (f) The unexposed SU-8 areas are removed by immersion in SU-8 developer followed by a hard bake step to cure the photoresist. 


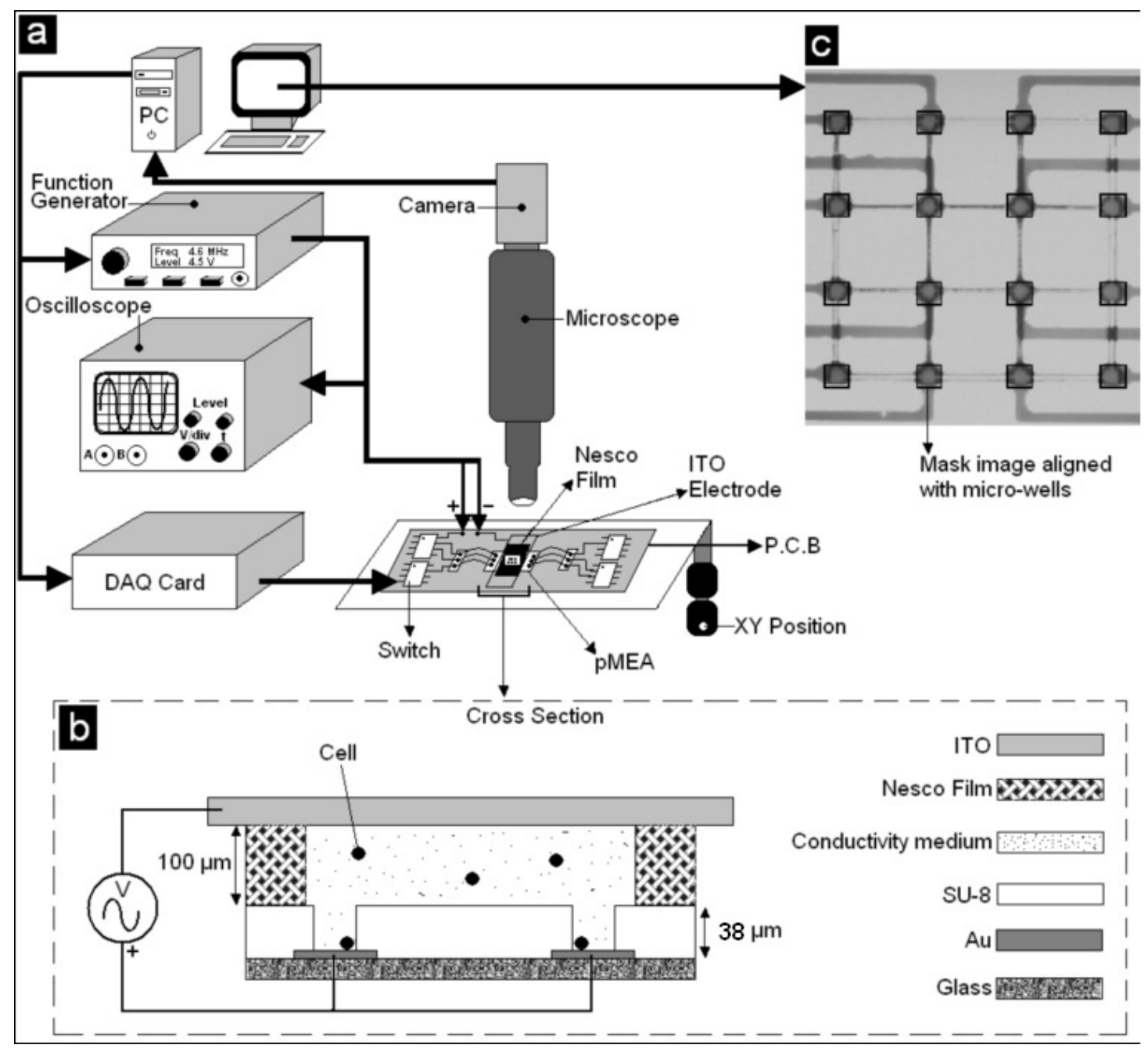

Fig. 3. Single cell positioning system. (a) The set-up comprises a microscope camera, a function generator and a data acquisition card (DAQ card), which are controlled by Matlab, a microscope, an oscilloscope and a P.C.B, which consists of 16-digitally controlled (via the DAQ card) analogue CMOS switches. Each of the sixteen electrode pads in the pMEA is connected to the output of one CMOS switch. The inputs of all the switches are connected to the positive terminal of the function generator. A $100 \mu \mathrm{m}$ thick sealing film surrounds the electrode site array of the pMEA. Approximately $20 \mu \mathrm{l}$ of cells suspended in a low conductivity medium are dropped on top of the electrode site area and covered by an ITO electrode, which is connected to the ground terminal of the function generator. (b) Cross section of the pMEA surrounded by a sealing film and covered by the ITO electrode. The pMEA 
was placed on a hotplate at $100{ }^{\circ} \mathrm{C}$ for 1 minute to form a liquid-tight chamber. (c) The micro-wells are aligned with a mask image, which consists of 16 squares that overlay the image of the wells. During single-cell positioning, Matlab captures an image and compares the difference in pixel value for the sixteen regions of interest between the current image and the image captured in the previous iteration. If the difference in pixel value for a specific region of interest exceeds a specified threshold value (i.e. a cell is positioned inside the micro-well) then the switch, which corresponds to that region, is opened in order to prevent the attraction of more cells to that micro-well. 


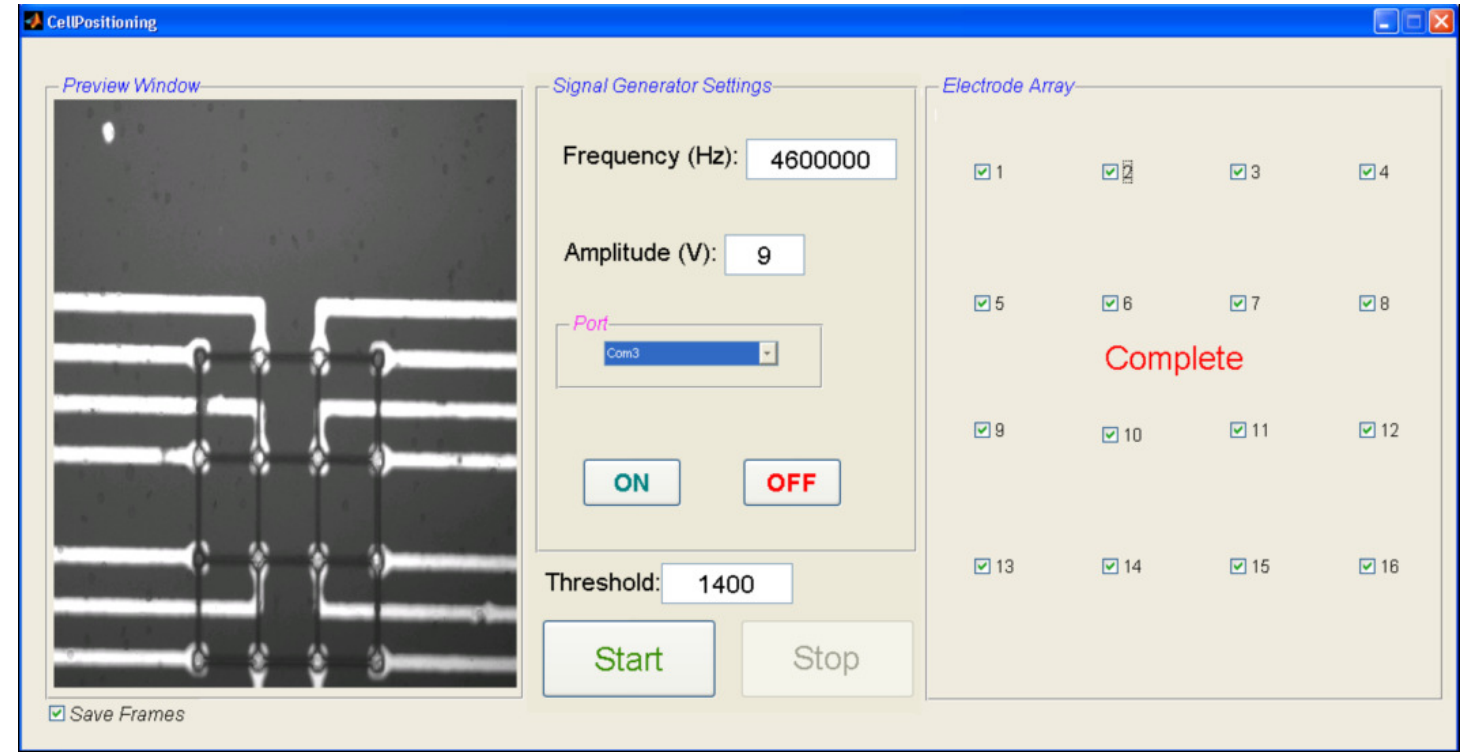

Fig. 4. User interface of Matlab GUI programme. The frequency $(\mathrm{Hz})$ and amplitude $\left(\mathrm{V}_{\mathrm{pp}}\right)$ for the sinusoidal output of the function generator can be set under the Signal Generator Settings panel. The operator can also select the PC serial port that would control the instrument and is also able to test its operation using the 'ON' and 'OFF' buttons. After, inputting the desired threshold value and clicking the 'Start' button the cell positioning session begins. The ticked checkboxes on the right-hand side panel (Electrode Array) indicate the micro-wells that have been loaded with cells. A Preview Window of the camera view is located on the left-hand side in order to monitor the process. 


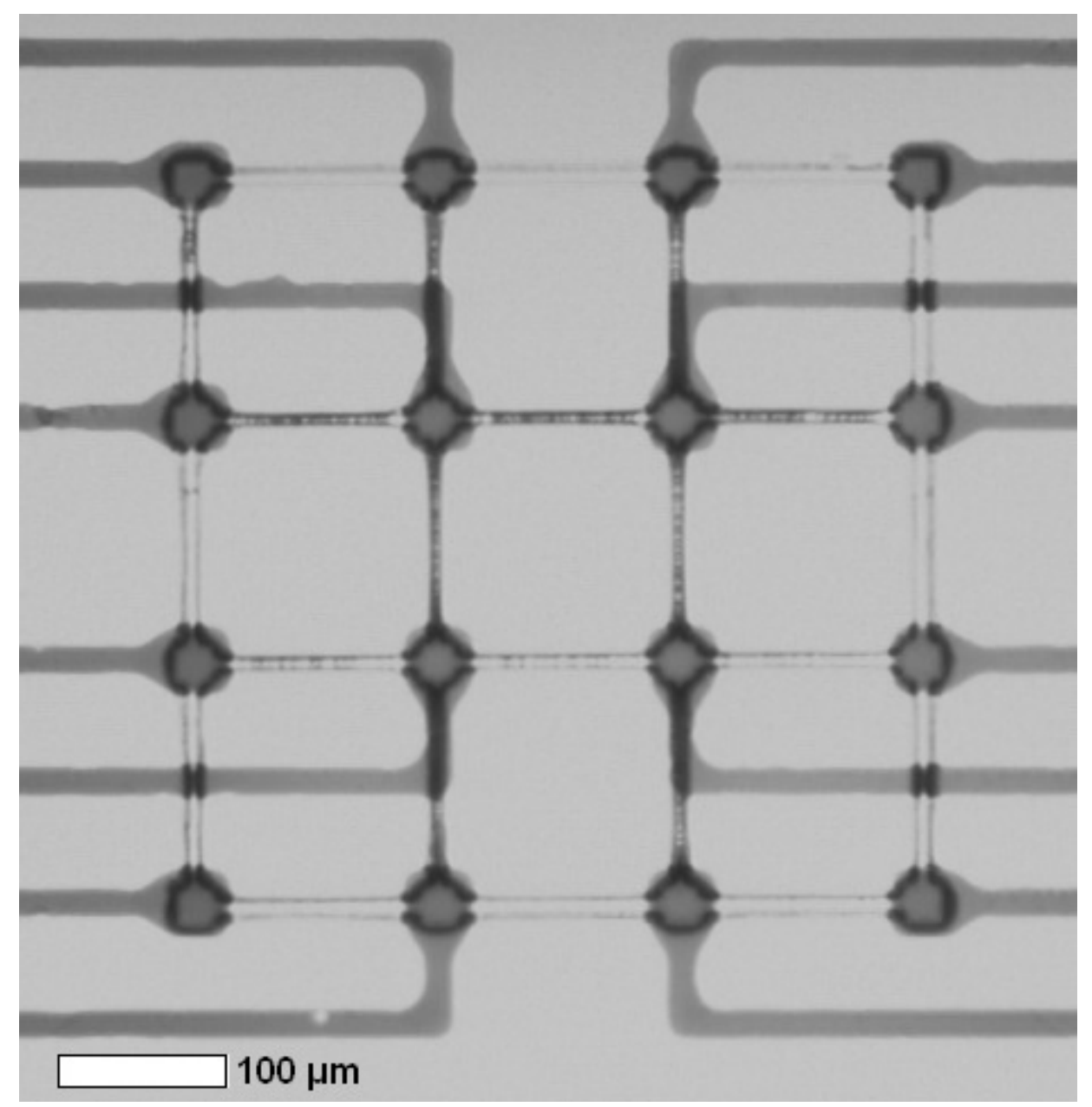

Fig. 5. SU-8 micro-wells and micro-trenches created on top of the pMEA. Due to the poor resolution of the emulsion mask, there is a large variation in the width of the micro-trenches, which is clearly visible in this image. Scale bar is a $100 \mu \mathrm{m}$ long. 


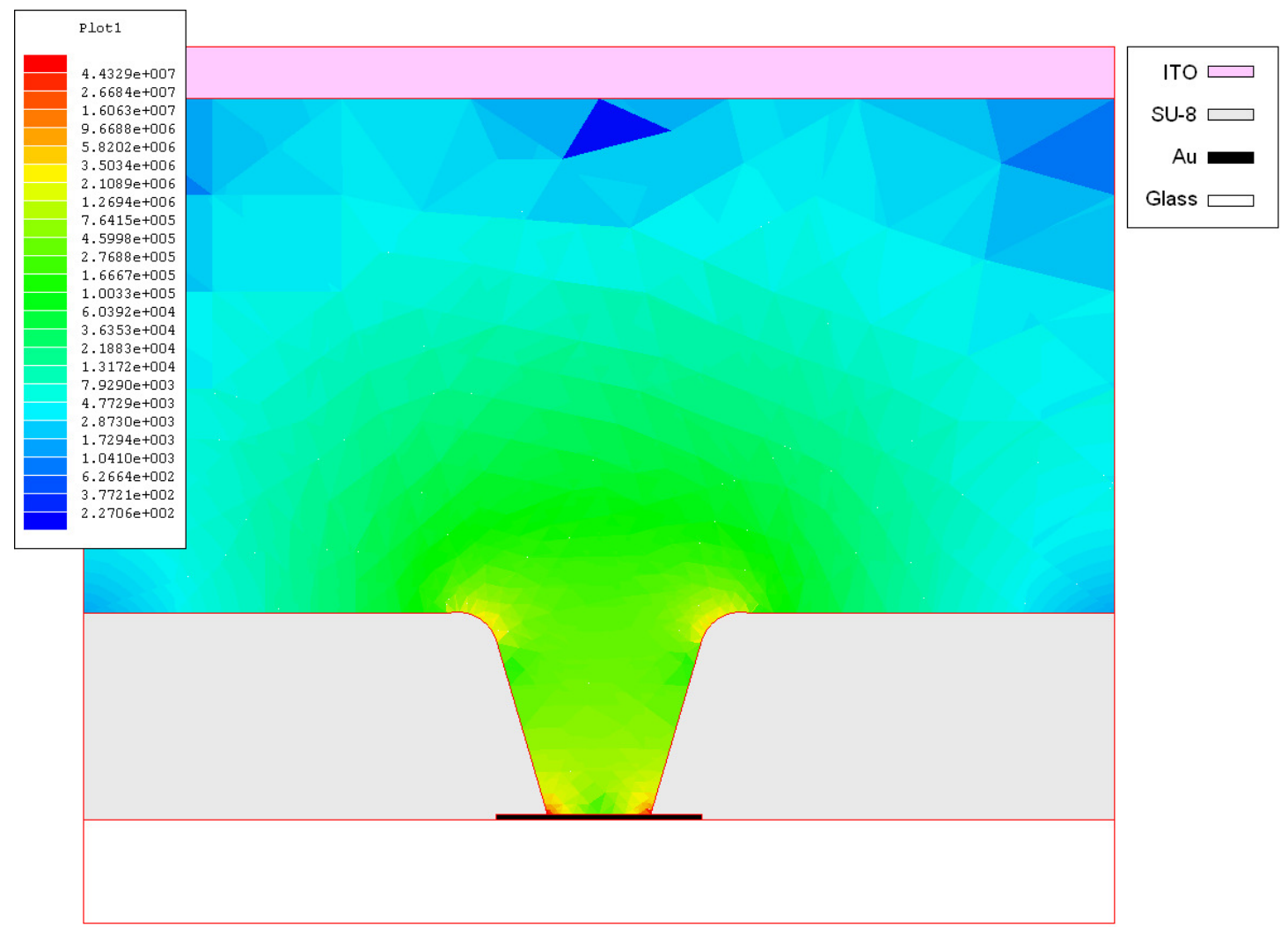

Fig. 6. FEM of the electrical field distribution over the surface of an SU-8 micro-well. The high field regions appear to be at the bottom edges of the micro-well indicating that neurons will be dielectrophoretically positioned there. 

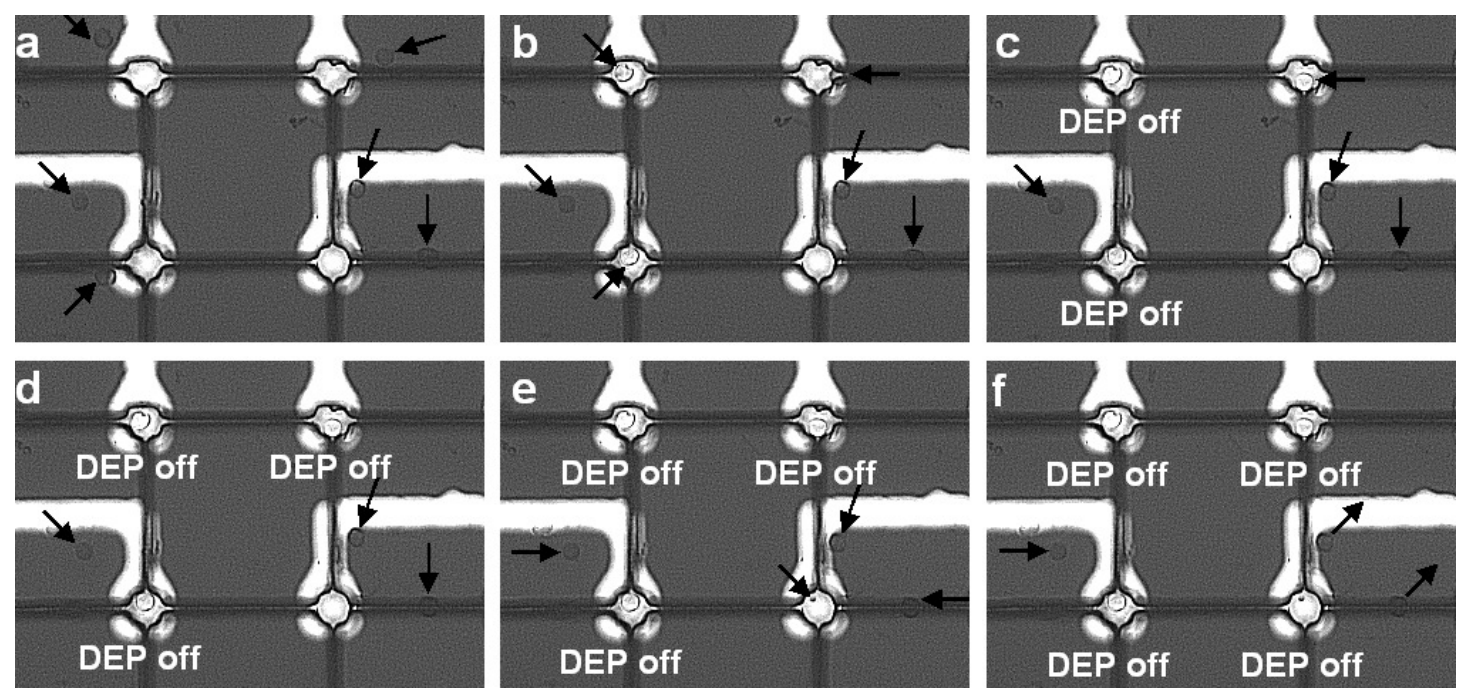

Fig. 7. Frame by frame loading of four micro-wells using the single-cell DEP positioning system. The time delay between frames is $417 \mathrm{~ms}$. Arrows show the direction of movement of cells and the 'DEP Off' sign indicates that the electric field has been switched off from that particular microelectrode. After switching off the electric field from the bottom two electrodes, the direction of movement of nearby cells changed, as they were not attracted to the electrode sites any more.
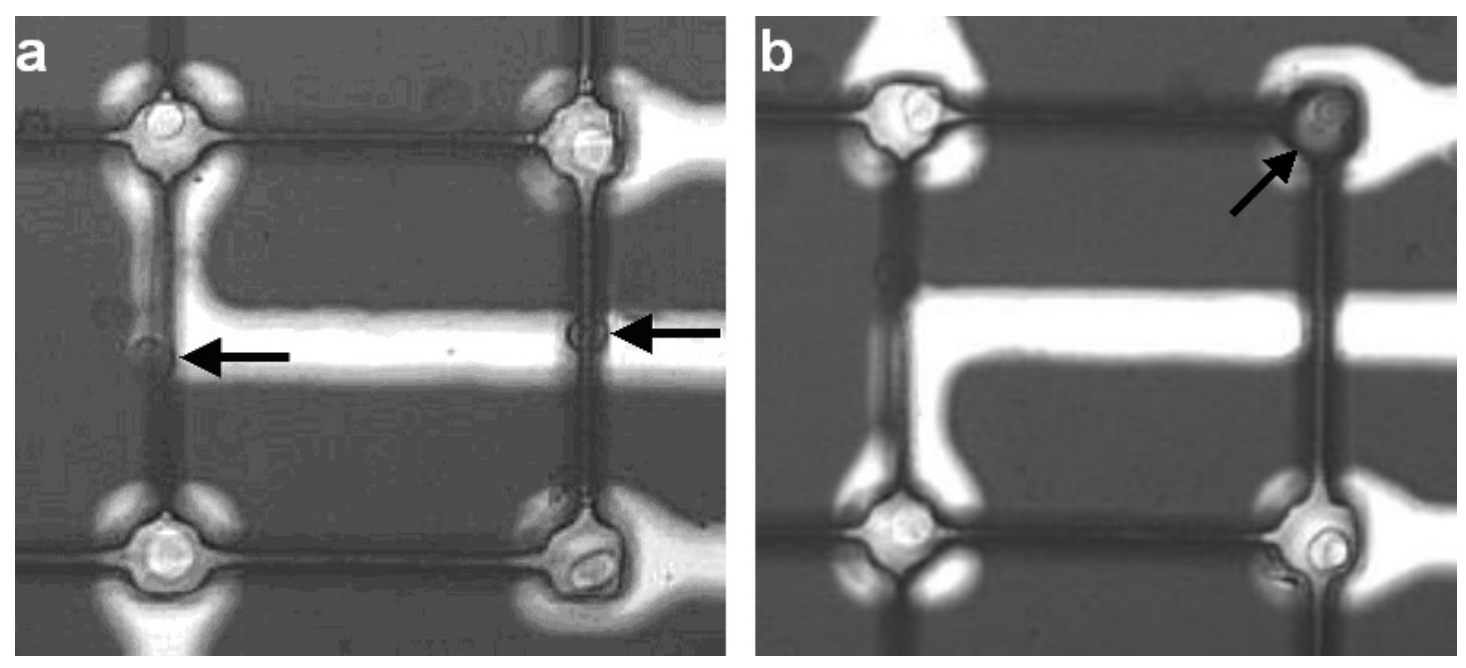

Fig. 8. (a) Neurons dielectrophoretically attracted to the tracks of the electrode sites because of the micro-trenches that extend across them. (b) Top right micro-well appears dark due to the presence of an air bubble. A cell lying inside the dark well is barely visible. The software did not recognise its presence and did not switch off the electric field. 


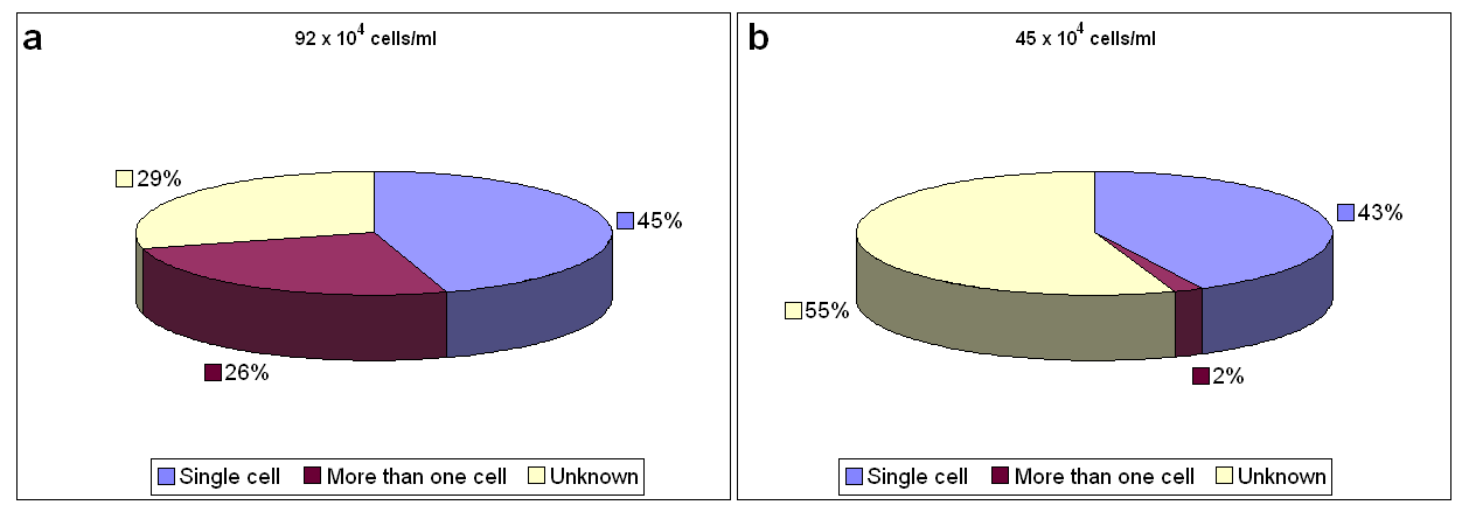

Fig. 9. DEP single-cell positioning statistics for two different cell concentrations. (a) Using a cell suspension with $92 \times 10^{4}$ cell/ml concentration $45 \%$ of micro-wells were positioned with a single well and $26 \%$ had more than one cell. The area marked unknown shows the percentage of dark wells occupied by air bubbles. (b) Using a lower cell concentration $\left(45 \times 10^{4}\right.$ cells $\left./ \mathrm{ml}\right)$ resulted in a significantly lower percentage of more than one cells being positioned inside the wells. The percentage of single cells was almost the same as the higher concentration (43\%); however, this was due to the high percentage of dark wells $(55 \%)$.
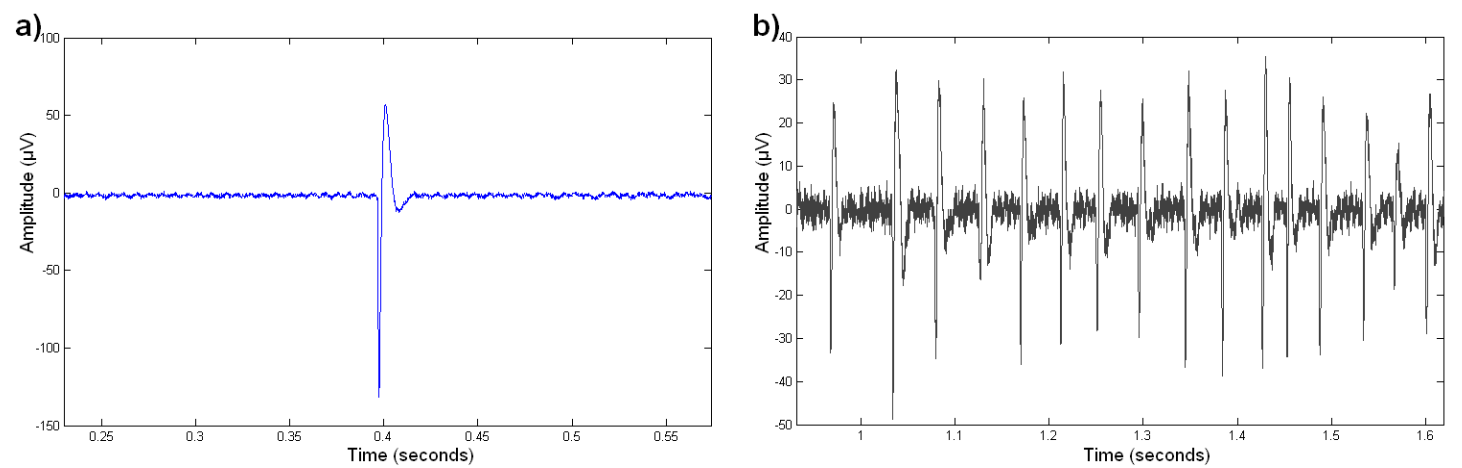

Fig. 10. Spontaneous activity recorded from DEP-positioned cells on pMEAs after 5 DIV. (a) Single action potential recorded at channel 15. (b) Typical burst recorded at channel 7. 


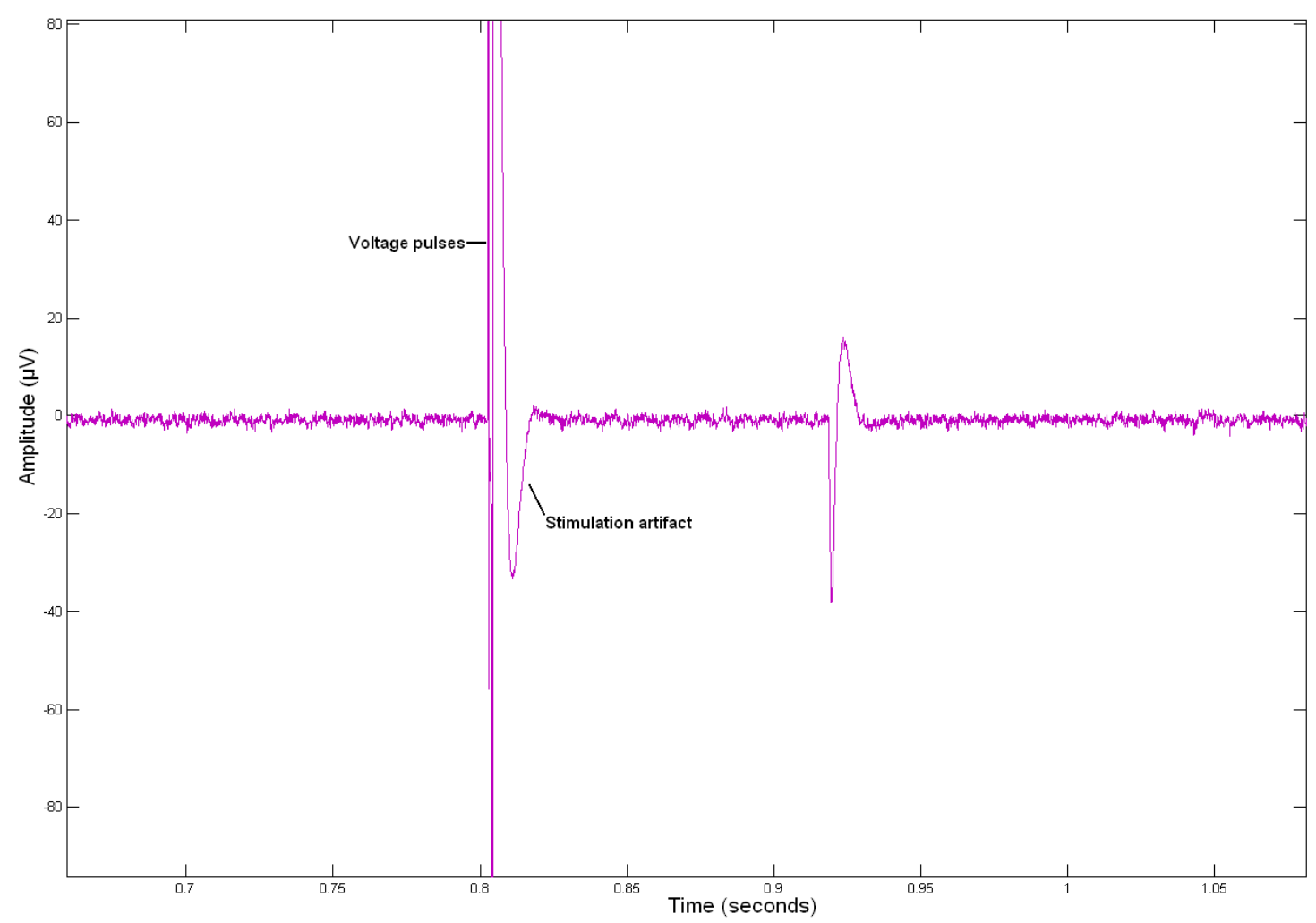

Fig. 11. Evoked action potential detected at channel 10 after $115 \mathrm{~ms}$ of applying two biphasic voltage pulses with a $500 \mu$ s duration and $1 \mathrm{~V}$ amplitude each. Artifacts due to stimulation pulses and the stimulation selector switch are clearly visible.
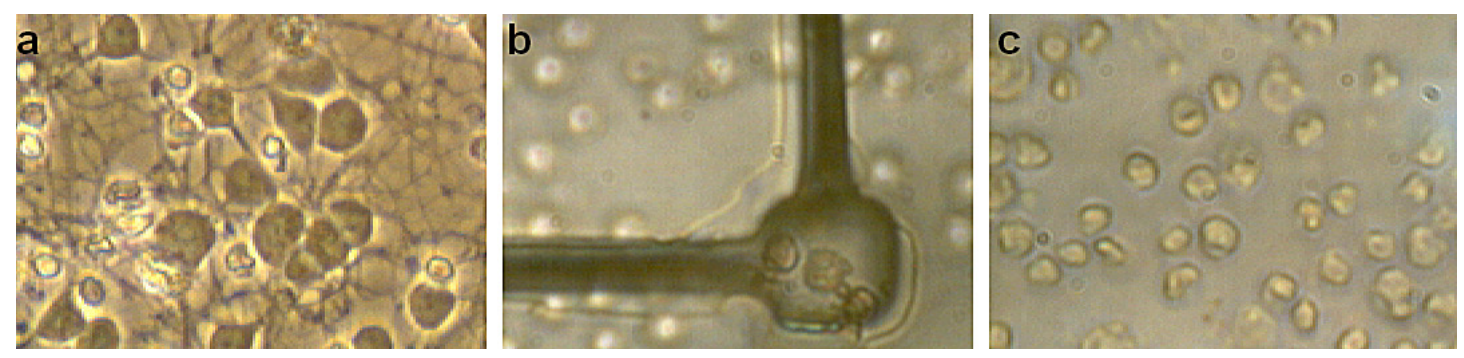

Fig. 12. Postnatal cerebellar rat neuron growth after 7 DIV. (a) On PDL-coated glass coverslips. (b) Inside a PDL-coated micro-well (not DEP-positioned). (c) On PDLcoated SU-8 2015 film. Neurons cultured inside micro-wells and on SU-8 did not demonstrate neurite growth and had irregular shapes, while the ones grown on glass coverslips succeeded in forming networks. 